\title{
Cervical cancer burden in Latin America and the Caribbean: Where are we?
}

Sophie Pilleron ${ }^{1^{\star}}$, Citadel J Cabasag ${ }^{2 \star}$, Jacques Ferlay ${ }^{2}$, Freddie Bray ${ }^{2}$, Silvana Luciani ${ }^{3}$, Maribel Almonte $^{1}$, Marion Piñeros ${ }^{2}$

\section{Affiliations}

${ }^{1}$ Prevention and Implementation Group, Section of Early Detection and Prevention, International Agency for Research on Cancer, Lyon, France

${ }^{2}$ Section of Cancer Surveillance, International Agency for Research on Cancer, Lyon, France

${ }^{3}$ Chief, Unit of Non-communicable Diseases, Violence and Injuries Prevention, PAHO,

Washington

Corresponding author: Sophie Pilleron, Prevention and Implementation Group, Section of Early Detection and Prevention, International Agency for Research on Cancer, 150 Cours Albert Thomas, 69008 Lyon, France. Phone: +33 (0)4 7273 8893; Fax: +33 (0)4 7273 8696; email: sophie pilleron@hotmail.com

Alternate corresponding author: Citadel Cabasag, Cancer surveillance section, International Agency for Research on Cancer, 150 Cours Albert Thomas, 69008 Lyon, France. Phone: +33 (0)4 7273 8175; Fax: +33 (0)4 7273 8022; email: cabasagc@fellows.iarc.fr

* equally contributed

\section{Keywords:}

Cervical cancer, Latin America and the Caribbean, incidence, mortality, epidemiology, cancer registry

\section{List of abbreviations}

This article has been accepted for publication and undergone full peer review but has not been through the copyediting, typesetting, pagination and proofreading process which may lead to differences between this version and the Version of Record. Please cite this article as doi: $10.1002 /$ ijc.32956. 
ASR: Age-standardised rate; $\mathrm{Cl5}$ : Cancer Incidence in five continents; EAPC: Estimated average annual percentage change; HDI: Human Development Index; GICR: Global Initiative for Cancer Registry Development; HPV: Human papillomavirus; IARC: International Agency for Research on Cancer; ICD: International Classification of Disease; LAC: Latin America and the Caribbean; PAHO: Pan American Health Organization; PBCR: Population-based cancer registry; WHO: World Health Organization 


\section{Novelty and Impact}

We described the cervical cancer incidence and mortality in Latin America and the Caribbean. In 2018, we estimated 56,000 and 28,000 new cervical cancer cases and deaths, respectively, with great variations between countries/territories. Despite a recent decrease in cervical cancer incidence and mortality rates, they are still high. Thus, achieving the elimination of cervical cancer in the Region still requires substantial effort, including the establishment of populationbased cancer registries. 


\begin{abstract}
In May 2018, the World Health Organization (WHO) called for the elimination of cervical cancer. To monitor this Initiative, we examined cervical cancer incidence and mortality in the Latin America and Caribbean (LAC) region using GLOBOCAN 2018, Cancer Incidence in Five Continents Series, and the World Health Organization Mortality Database. We estimated the number of cases and age-standardized rates (ASRs) for cervical cancer incidence and mortality for 2018. We also presented the ASRs for recorded cervical cancer incidence from the 20082012 period. We calculated annual rates and analysed trends in cervical cancer incidence and mortality for all ages combined and for the following age groups: 0-29; 30-49; 50-64; 65+. Finally, we calculated the estimated average annual percentage change in incidence and mortality rates for the past ten years. In 2018 , an estimated 56,000 new cervical cancer cases and 28,000 cervical cancer deaths occurred among women in LAC, with great variations between sub-regions and countries/territories. Overall, trends in cervical cancer incidence and mortality have decreased over the past decade; however, the rates are still above the elimination threshold of 4 per 100,000 in most LAC countries/territories. Despite the encouraging trends observed, achieving the elimination of cervical cancer in the Region still requests substantial political commitment and economic effort. Population-based cancer registries are critical in monitoring the elimination Initiative.
\end{abstract}

This article is protected by copyright. All rights reserved. 


\section{Introduction}

With more than 570,000 new diagnoses and 311,000 new deaths worldwide in 2018, cervical cancer ranks fourth in cancer incidence and mortality and remains one of the leading cancers among women worldwide ${ }^{1}$. Lower resourced countries bear the largest burden from this preventable disease, with over $80 \%$ of the global cervical cancer new cases and deaths in lowand-middle-income countries ${ }^{2,3}$. Although marked declines have been observed in incidence rates worldwide, cervical cancer continues to disproportionally affect women in Latin America and the Caribbean (LAC), relative to most other regions. Recent reports ranked cervical cancer as the third most common cancer diagnosed in the LAC region ${ }^{2}$, with considerable variations in incidence and mortality between countries; cervical remains the leading cause of cancer in women in 11 of the 32 countries/territories with estimated cancer data available ${ }^{3-5}$.

In May 2018, the World Health Organization (WHO) called for a global scale-up of cervical cancer control that would lead to the eventual elimination of the disease ${ }^{6}$. Specifically, the WHO draft global strategy has established that "cervical cancer should no longer be considered a public health problem when the age-adjusted incidence rate is less than 4 per 100,000 women year"7. The strategy aims that "90\% of girls fully vaccinated with the human papillomavirus vaccine by 15 years of age; $70 \%$ of women are screened with a high-precision test at 35 and 45 years of age; and 90\% of women are identified with cervical disease receive treatment and care"7. In September 2018, the Pan American Health Organization (PAHO) Directing Council endorsed a regional plan of action for cervical cancer prevention and control to reduce incidence and mortality rates by $30 \%$ by $2030^{8}$. 
Currently, 29 of 47 countries/territories in the LAC region have implemented human papillomavirus (HPV) vaccination programs in girls and almost all countries/territories have screening services in place, and while certain screening programs in the region reach a sizeable coverage $^{8}$, they are yet to reach the ambitious targets set by the elimination strategy $y^{5,9}$. In addition, although advances in treatment have been made in the LAC region, documented barriers to access treatment persist ${ }^{11,12}$.

Population-based cancer registries (PBCR) are critical in planning, monitoring and evaluating the success of the required national vaccine, screening and treatment actions towards the goal of cervical cancer elimination. Nevertheless, less than half of the countries in the $L A C$ region have a high-quality PBCR, with less than $10 \%$ of the population covered by such registries in the region ${ }^{13}$.

The present study examines the current cervical cancer burden in 32 countries/territories in the Latin America and Caribbean region, providing the most up-to-date data as a means to inform and monitor the Elimination Initiative in the Region.

\section{Materials and methods}

\section{Data sources}

Estimated incidence and mortality

Cervical cancer (International Classification of Disease 10 $0^{\text {th }}$ edition, ICD-10: C53) incidence and mortality estimates for the year 2018 were obtained for 32 countries/territories in LAC (see list in Table 1), by five-year age group $(0-4,5-9, \ldots, 80-84$, and 85 and over) from the GLOBOCAN database ${ }^{14}$ compiled by the International Agency for Research on Cancer (IARC). 
Detailed methodology used in GLOBOCAN 2018 have been previously published elsewhere ${ }^{15}$; the data are presented within the Global Cancer Observatory (http://gco.iarc.fr).

\section{Observed incidence}

Data on cervical cancer incidence by five-year age group and corresponding population were obtained from Cancer Incidence in Five Continents Volume $\mathrm{XI}^{16}$, which includes highquality global incidence data from national and sub-national PBCRs. We included data from 31 PBCRs in twelve countries/territories in LAC covering the 2008-2012 period (detailed in Table 2): Argentina (5 PBCRs), Brazil (6 PBCRs), Chile (4 PBCRs), Colombia (4 PBCRs), Costa Rica (national PBCR), Ecuador (5 PBCRs), France, Martinique (1 PBCR), French Guiana (1 PBCR), Jamaica (1 PBCR), Peru (1 PBCR), Puerto Rico (national PBCR), and Uruguay (national PBCR). For the assessment of time trends, annual incidence data and corresponding annual population data were extracted for PBCRs with incidence data for at least 15 consecutive years (i.e. Goiania, Brazil; Valdivia, Chile; Cali, Colombia; Costa Rica; Quito, Ecuador; Martinique, France) extracted from the $\mathrm{Cl} 5$ plus database ${ }^{17}$.

Recorded incidence by PBCR may differ from the corresponding country-specific GLOBOCAN 2018 estimates due to the differences in the methods used to calculate the rates, as well as, data availability and timeliness. Thus, a direct comparison between the two measures is not possible.

\section{Observed mortality}

Cancer mortality data by five-year age group for 32 LAC countries/territories were obtained from the WHO Mortality Database ${ }^{18}$ that provides mortality data by age, sex and cause 
of death as reported by WHO Member States (http://www.who.int/healthinfo/mortality data/en/). Population data were obtained from the United Nations Population Prospect ${ }^{19}$ by five-year age group for all 32 LAC countries/territories. We extracted all deaths coded as "malignant neoplasm of cervix uteri" (180 in ICD-9 and C53 in ICD-10), "malignant neoplasm of corpus uteri" (182 in ICD-9, and C54 in ICD-10), or "malignant neoplasm of uterus, part not specified" (179 in ICD-9 and C55 in ICD-10).

$\underline{\text { Reallocation of ill-defined deaths and uterine cancer, unspecified part }}$

We reallocated uterus cancer deaths coded as 'uterus, part unspecified' to cervix uteri and corpus uteri independently by country, year and age group using an algorithm adapted from Diama Vale and colleagues ${ }^{20}$, in four steps as described in Supplementary Figure 1:

1) We reallocated ill-defined causes of death proportionally between cancer-related deaths and other causes of deaths except for injury.

2) We redistributed these additional cancer-related deaths proportionally among cancer sites.

3) We proportionally reallocated deaths from cervix uteri, corpus uteri and "malignant neoplasm of uterus, part not specified" with unknown age into the known age groups.

4) We reallocated ill-defined uterine cancer deaths into cervical cancer deaths and uterine cancer deaths with varying methods depending on age at death.

As cancer of the corpus uteri is very rare among women below the age of 50 , all illdefined uterine cancer deaths in women aged less than 50 years were therefore assigned to cervical cancer deaths. For older women, we reallocated proportionally ill-defined uterine cancer deaths to cervical cancer deaths and uterine cancer deaths. 
During the period when ICD-9 was utilized, all countries/territories (except for Chile in 1983, Cuba in 2000, Guatemala in 2000-2004, and Venezuela in 1980) did not report deaths coded as "malignant neoplasm of uterus, part not specified" (ICD-9: 179) and corpus uteri cancer deaths (ICD-9: 182) deaths separately; instead, these two categories were grouped under the category coded B122. To redistribute deaths coded B122 between corpus uteri and cervix uteri cancer deaths, we applied the percentage of cervical cancer deaths of the earliest year of ICD-10 use. For example, for Argentina and Brazil, we used the proportion of C53 for the year 1996 to redistribute cancer deaths for the years 1979-1995.

\section{Trends}

For incidence trends, we included data from PBCRs in Goiania (Brazil), Valdivia (Chile), Cali (Colombia), Costa Rica and Quito (Ecuador), Martinique (France) (six countries out of 32 LAC countries/territories). For mortality trends, we included Argentina, Brazil, Chile, Colombia, Costa Rica, Cuba, Dominican Republic, Ecuador, El Salvador, Guatemala, Mexico, Nicaragua, Panama, Paraguay, Peru, Puerto Rico, Trinidad and Tobago, Uruguay, and Venezuela (19 countries out of 32 countries/territories). We excluded countries with less than 50 annual deaths (Bahamas, Barbados, Belize, French Guyana, France, Guadeloupe and Martinique, Guyana, Haiti, Honduras, Saint Lucia, Suriname) and those with missing data for more than two consecutive years (Bolivia (available years: 2000-2003)), Jamaica (missing years: 1982, 1984, 1992-1999, 2007-2008, 2012-2015)).

Data analysis

This article is protected by copyright. All rights reserved. 
The estimated number of cases and estimated age-standardized rates (ASRs) for cervical cancer incidence and mortality with 95\% confidence interval were reported, using the World standard population ${ }^{21}$ for each of the 32 LAC countries/territories included in GLOBOCAN 2018. Additionally, new observed cases were presented and the ASRs for observed cervical cancer incidence were calculated for the 31 PBCRs included in $\mathrm{CI} 5$ Volume XI.

We analyzed trends in cervical cancer incidence and mortality for all ages combined and for the following age groups: 0-29; 30-49; 50-64; 65+. Annual ASRs for incidence and mortality were calculated. For each country, to graphically summarize the trends, we fitted quasi-Poisson models with a cubic spline effect for year with three knots placed at quartiles of the variable year and an interaction term between age group and year to provide smoothed lines through the scatterplot of ASRs by year and age group. Rates are plotted on a semi-log scale. In addition, we calculated the estimated average annual percentage change (EAPC) in incidence and mortality rates, and its 95\% confidence interval using adjusted quasi-Poisson regression models with a linear effect for year of incidence/death and an interaction term between year and age group to obtain EAPC for each age group. Quasi-Poisson models were privileged to account for over-dispersion.

\section{Data availability}

The data that support the findings of this study are openly available within the Global Cancer Observatory at http://gco.iarc.fr ${ }^{14}$ for the 2018 GLOBOCAN estimates, the Cancer Incidence in Five Continents for the annual incidence data at http://ci5.iarc.fr/Default.aspx ${ }^{22}$ and the WHO Mortality Database for the mortality data at 
http://www.who.int/healthinfo/mortality_data/en/ ${ }^{18}$. Datasets used for the analysis will be made available upon reasonable request.

\section{Results}

Cervical cancer burden in Latin America and the Caribbean in 2018

In 2018, an estimated 56,000 new cervical cancer cases and 28,000 cervical cancer deaths occurred among women in LAC, representing around $10 \%$ of the total global number of new cervical cancer cases $(569,000)$ and $9 \%$ of the total global cervical cancer deaths $(311,000)$. An estimated 39,600 new cervical cancer cases and 19,200 cervical cancer deaths in the region occurred in South America alone (Table 1). The age-standardised incidence and mortality rates in the LAC region were 14.6 and 7.1 per 100,000 respectively, with the disease ranking second in LAC after the African region (27.6 and 20.0, respectively) and slightly higher than the global rates (13.1 and 6.9, respectively) (Supplementary Figure 2). Incidence rates were lower in Central America (13.0 per 100,000) than in South America (15.2) and the Caribbean (15.5) while mortality rates were higher in the Caribbean (8.5) than in South America (7.1) and Central America (7.0) (Table 1 - Figure 1). At the country level, Martinique exhibited the lowest incidence and mortality rates in 2018 (7.6 and 1.9, respectively), while Bolivia had the highest estimated incidence rate (38.5) and Jamaica the highest mortality rate (20.1) (Figure 1).

Recorded cervical cancer incidenceTable 2 presents the recorded cervical cancer incidence in selected PBCRs for the period 2008-2012. The lowest incidence rate was observed in Poços de Caldas, Brazil (6.8 per 100,000) and the highest in Chaco, Argentina (26.5). Incidence rates 
varied greatly between populations within the same country. For example, the ASR ranged from 8.9 in Tierra del Fuego to 26.5 in Chaco in Argentina or from 6.8 in Poços de Caldas to 15.6 in Florianopolis in Brazil.

Trends in cervical cancer incidence in selected LAC populations

Figure 2 shows the trends in cervical cancer incidence rates, and Table 3 presents the EAPC for all ages combined and by age group for six PBCRs in LAC. For all ages combined, incidence rates are rather stable in Quito, Ecuador ( $+0.4 \%$ yearly on average over the ten past years) and in Costa Rica (-0.7\%), while incidence rates are decreasing in Cali, Colombia (-4\%), Valdivia, Chile (-6\%) and Goiania, Brazil (-4\%) and appear to decrease in Martinique (-3\%) over the same period. Overall, incidence rates are increasing as age increases irrespective of period of diagnosis (Figure 2). Over the most recent decade, incidence rates have significantly increased for the 0-29 year age group in Costa Rica (+11\% yearly on average) and, despite the negative lower bound of the confidence interval, the same tendency is observed for Valdivia, Chile (+16\% - Table 3). Among women aged 50 and older, incidence rates are, in general, decreasing, since the mid-1990s in most countries/territories, with the EAPC ranging from $-4 \%$ in Ecuador and Costa Rica to $-15 \%$ in Martinique in women aged $50-64$ years and from -2\% in Martinique to $-10 \%$ in Brazil in women aged over 65 (Table 3). Ecuador, Quito is an exception with a tendency of increasing rates in women aged 65 years or older (Table 3).

Trends in cervical cancer deaths in selected LAC countries/territories

Figure 3 illustrates the trends in cervical cancer mortality rates and Table 3 presents the EAPC for all ages combined and by age group in the 19 countries/territories where mortality 
data were available. Over the past ten years, mortality rates for all ages combined have slightly increased in Puerto Rico (+2\%), decreased in Chile (-2\%), Colombia (-2\%), Ecuador (-3\%), Cuba (-1\%), El Salvador (-4\%), Mexico (-2\%), and Paraguay (-2\%) and stayed stable in the remaining countries. Mortality rates among the 0-29 year age group tended to decrease for all countries/territories, except for Brazil, where the mortality rates have significantly increased $(+4 \%)$. The majority of countries/territories exhibited decreasing mortality rates at ages 30 years and older.

\section{Discussion}

This study provides the most up-to-date picture of the cervical cancer burden in LAC, in LAC, and illustrates the continuation of decreasing trends in cervical cancer, as has been shown in previous analyses ${ }^{23}$. Overall, cervical cancer remains a major health problem in the region. The encouraging decrease in incidence and mortality rates over the last decade observed among women aged over 30 , is tempered by the observation that, in absolute terms, the rates were 10 above the elimination threshold of 4 per 100,000 in most LAC countries/territories. This study also illustrates the scarcity of high-quality reported incidence data in the region with only 31 PBCRs from 12 of 32 countries providing 2008-2012 incidence rates. This clearly highlights the need for the development of new PBCRs in most countries and the improvement of data quality in many existing registries.

The LAC region comprises a diverse set of countries/territories, which challenges the implementation of health policies that may serve to increase disparities if systems are not uniformly in place to support such actions. Variations in the incidence and mortality rates 
between countries/territories in the LAC region appear to be correlated with their national human development index, as well as the robustness of the health system to implement comprehensive cervical cancer programs. For instance, the highest estimated cervical cancer incidence rates were estimated in Bolivia and Jamaica, both of which have a low Human Development Index (HDI). Furthermore, intra-country variations in cervical cancer incidence are also observed in most countries/territories; in Argentina, the highest rates were observed in El Chaco, which is one of the provinces in Argentina with a lower $\mathrm{HDI}^{24}$. Thus the marked differences in economic development and inequalities in access to screening may also potentially contribute to the disparities in cervical cancer incidence rates ${ }^{25,26}$.

Despite the high incidence rates in many countries/territories, we found a declining incidence of cervical cancer in selected PBCRs, particularly in Brazil, Chile, and Colombia. The decrease in incidence over time has been previously reported in the Region ${ }^{27}$. This decrease may be attributed to multiple factors, including declines in fertility rates, lower parity, and improvements in socioeconomic and education levels ${ }^{3,27,28}$, as well as having well-structured screening and treatment programs with relatively higher screening coverage. While some LAC countries/territories have implemented cervical cancer screening programs in the past decade, the impact of screening may be limited to those populations due to suboptimal coverage and follow-up, unequal access to health care, and low adherence to the screening process ${ }^{29}$. Congruent with the decline in incidence and with previous reports, we also observed a consistent decline in cervical cancer mortality rates for the majority of the LAC countries/territories over time, while rates remained stable in a few countries, including Argentina and Brazil ${ }^{30-33}$. This decrease in mortality rates is likely attributable to the better 
education of women who seek screening and advances in treatment ${ }^{34}$. Contrary to previous studies $^{35}$, we observed an increase in cervical cancer mortality rates in Puerto Rico over the past decade, mainly driven by increasing mortality among the 30-49 year age group. Although the reason for the rise is unclear, it could be linked to diagnosis at a more advanced-stage disease in this age group that has been associated with a lower prognosis ${ }^{36}$. Economic and societal development factors related to improved cancer prognosis may have also contributed to the decline in cervical cancer mortality in some LAC countries/territories, however, the specific determinants need further investigation.

Despite persistent declines in incidence and mortality, rates remain highest in women over the age of 65 in all LAC countries/territories. Several factors may contribute to the high incidence of cervical cancer among older women. While women over the age of 65 are no longer targeted by cervical cancer screening ${ }^{5}$, they may also be more likely to have comorbidities that would increase their likelihood of contact with the healthcare system, although some studies have reported that a higher level of comorbidity decreased the likelihood of screening participation ${ }^{37}$. Furthermore, cervical cancer management among older women may be complicated by anatomical changes of the cervix, a higher level of comorbidities, and lower performance status, leading to sub-optimal treatment compared to younger women ${ }^{38}$. Furthermore, older women who develop cervical cancer are also more likely to be diagnosed with advanced-stage disease, contributing to higher mortality rates in this age group ${ }^{39}$. With the expected population growth among older women in the LAC region over the next decades ${ }^{40}$, there is an overwhelming need for cervical cancer control programs and policies tailored to older women in LAC countries/territories. 
This study has reported increased incidence rates among the youngest age group (0-29 years) in some certain cancer registries in the LAC region, although incidence and mortality estimates in this group should be interpreted with caution due to the relatively small number of cases and deaths. Our findings emphasize the importance and the need to continue efforts in improving HPV vaccination coverage in these countries/territories, while also improving the effectiveness of screening and treatment programs. A recent modeling study, including Bolivia, El Salvador, Haiti, Honduras, and Nicaragua, showed that cervical cancer elimination in all of the 5 LAC countries could be reached by 2120, provided that the HPV vaccination coverage is $90 \%$ and there is at least one screening at 35 years $^{41}$. However, only $80 \%$ of LAC countries would reach the elimination threshold with HPV vaccination alone. Furthermore, achieving the 90-70-90 WHO targets on cervical cancer would reduce cervical cancer mortality by more than $95 \%$ by $2120^{42}$. As of October 2019 , four-fifths, or 26 of the 32 , mainly middle-income countries/territories under study in the region had introduced HPV vaccination programs, the exceptions being El Salvador, Nicaragua, Venezuela, Haiti and Cuba ${ }^{43}$. Notably, a higher average vaccine coverage level among girls aged 10-14 years has been observed in Latin America compared to Northern America and some regions of Europe ${ }^{10}$.

It can be anticipated that there will be further decreases in cervical cancer incidence in the future. It will take decades before the impact of HPV vaccination will be observable at the population level. Therefore, screening pre-cancerous cervical lesions remains essential in lowering cervical cancer incidence. These programs should be reinforced and implemented in all LAC countries/territories. 
Our study has limitations. The accuracy of GLOBOCAN 2018 estimates is dependent on the availability and of the quality of national or sub-national incidence and mortality data, thus these estimates should be interpreted with some caution. In countries where national mortality data are available, but national or subnational cancer registries are not (e.g. Venezuela, Nicaragua), the national incidence estimates relied on national mortality estimates and modelling of the mortality to incidence ratio from neighboring countries ${ }^{15}$.

Although good vital systems are available in many LAC countries/territories, there is room for improvement in the vital registration of cervical cancer deaths, as indicated by the large disparities in the percentage of ill-defined uterine cancer deaths (ICD10: C55 - Supplementary Table 1). In the absence of validated methods to reallocate ill-defined uterine cancer deaths into cervical cancer deaths, we apply a reallocation process adapted from Bhadra and colleagues and Loos and colleagues ${ }^{20,44}$. However, when applying the same rule for reallocation in all countries/territories we assume that mortality data in all these countries have the same quality but that could be wrong.

Reliable cancer incidence data are critical for cancer surveillance and in monitoring progress towards the elimination of cervical cancer in the Region ${ }^{45}$. However, the paucity of high quality (and longstanding) available incidence data precludes monitoring trends in cervical cancer incidence in many LAC countries/territories. Having PBCRs in the region alone is not sufficient. There is a need to improve the data quality of existing PBCRs in many countries, as well as providing support and resources into the development of cancer registries in countries without existing PBCRs. IARC has been coordinating the Global Initiative for Cancer Registry Development (GICR), a multi-partner initiative that aims to improve the inequity in data 
availability and quality [https://gicr.iarc.fr/]. However, such an initiative can only be successful if countries/territories recognize that importance of having sustainable PBCRs with high-quality and reliable data to monitor cancer burden, as well as, to plan and evaluate cancer control activities. The PAHO Plan of Action on Cervical Cancer Prevention and Control has set a target of 19 countries to have PBCRs in place by 2030 and the Cervical Cancer Elimination Strategy sets a good opportunity to advance cancer registration as a means to monitor successes in moving towards this target.

\section{Conclusion}

In this study, we aim to provide a comprehensive description of the cervical cancer burden in Latin America and the Caribbean region as a means to inform the Cervical Cancer Elimination Initiative. While the decrease in incidence and mortality suggests improvements in screening and treatment, further investigation is needed to understand the underlying reasons for these declines. The incidence and mortality rates remain high in the region and highlight the need for increased efforts, political commitment and adequate funding to improve the effectiveness of existing cervical cancer programs on the road to the elimination of cervical cancer. These efforts necessarily includes the establishment and sustainable development of PBCRs in the LAC region as a comprehensive surveillance tool for cancer control.

\section{Acknowledgments}

The authors gratefully acknowledge population-based cancer registries worldwide and their staff for their willingness to contribute their data. We would like to thank Dr Hadrien Charvat for his statistical advice.

\section{Conflict of interest}

The authors declare that they have no conflicts of interest. 


\section{TABLES}

Table 1. Estimated cervical cancer incidence and mortality, numbers and rates (ASR per 100,000 women-year) in Latin America and the Caribbean, by country, 2018

Table 2. Recorded cervical cancer incidence cases and rates (ASR, per 100,000 women-year) in selected Latin American and the Caribbean registries, ca. 2008-2012

Table 3. Estimated annual percent change (EAPC, \%) and $95 \%$ confidence interval $(\mathrm{Cl})$ for cervical cancer incidence and mortality rates in selected Latin America and the Caribbean cancer registries and countries

\section{FIGURES}

Figure 1. Distribution of age-standardized incidence rates per 100,000 women-year by country and sub-region comparatively to the elimination threshold defined by WHO, 2018

Figure 2. Trends in cervical cancer incidence rates (ASR, per 100,000 women-year, log scale) in six selected cancer registries of Latin America and The Caribbean, all ages combined and by age groups, ca.1980-2012

Figure 3. Trends in cervical cancer mortality rates (ASR, per 100,000 women-year, log scale) in 19 Latin America and the Caribbean countries/territories, all ages combined and by age groups, ca.1979-2015

\section{References}

1. Arbyn M, Weiderpass E, Bruni L, de Sanjose S, Saraiya M, Ferlay J, Bray F. Estimates of incidence and mortality of cervical cancer in 2018: a worldwide analysis. Lancet Glob Health 2019.

2. Bray F, Ferlay J, Soerjomataram I, Siegel RL, Torre LA, Jemal A. Global cancer statistics 2018: GLOBOCAN estimates of incidence and mortality worldwide for 36 cancers in 185 countries. CA Cancer J Clin 2018;68: 394-424.

3. Vaccarella S, Laversanne M, Ferlay J, Bray F. Cervical cancer in Africa, Latin America and the Caribbean and Asia: Regional inequalities and changing trends. Int J Cancer 2017;141: 1997-2001.

4. Pierce Campbell CM, Curado MP, Harlow SD, Soliman AS. Variation of cervical cancer incidence in Latin America and the Caribbean. Rev Panam Salud Publica 2012;31: 4928.

5. Murillo R, Herrero R, Sierra MS, Forman D. Cervical cancer in Central and South America: Burden of disease and status of disease control. Cancer Epidemiol 2016;44 Suppl 1: S121-S30. 100170.

6. Canfell K. Towards the global elimination of cervical cancer. Papillomavirus Res 2019:

7. Draft: Global strategy towards the elimination of cervical cacner as a public health problem. World Health Organization, 2019. 
8. Pan American Health Organization, World Health Organization. 56th Directing Council: 70th Session of the Regional Committee of WHO for the Americas Washington D.C., 2018.

9. Murillo R, Almonte M, Pereira A, Ferrer E, Gamboa OA, Jeronimo J, Lazcano-Ponce E. Cervical cancer screening programs in Latin America and the Caribbean. Vaccine 2008;26 Suppl 11: L37-48.

10. Bruni L, Diaz M, Barrionuevo-Rosas L, Herrero R, Bray F, Bosch FX, de Sanjose S, Castellsague $X$. Global estimates of human papillomavirus vaccination coverage by region and income level: a pooled analysis. Lancet Glob Health 2016;4: e453-63.

11. Liebermann EJ, VanDevanter N, Shirazian T, Frias Guzman N, Niles M, Healton C, Ompad D. Barriers to Cervical Cancer Screening and Treatment in the Dominican Republic: Perspectives of Focus Group Participants in the Santo Domingo Area. J Transcult Nurs 2019: 1043659619846247.

12. Sardi A, Orozco-Urdaneta M, Velez-Mejia C, Perez-Bustos AH, Munoz-Zuluaga C, El-Sharkawy F, Parra-Lara LG, Cordoba P, Gallo D, Sittig M, King MC, Nieroda C, et al. Overcoming Barriers in the Implementation of Programs for Breast and Cervical Cancers in Cali, Colombia: A Pilot Model. J Glob Oncol 2019;5: 1-9.

13. Piñeros M, Abriata M, Mery L, Bray F. Cancer registration for cancer control in Latin America: a status and progress report. Pan American Journal of Public Health 2017.

14. International Agency for Research on Cancer. Global Cancer Observatory Lyon, France, 2019.

15. Ferlay J, Colombet M, Soerjomataram I, Mathers C, Parkin DM, Pineros M, Znaor A, Bray F. Estimating the global cancer incidence and mortality in 2018: GLOBOCAN sources and methods. Int J Cancer 2019;144: 1941-53.

16. Bray F, Colombet M, Mery L, Piñeros M, Znaor A, Zanetti R, Ferlay J. Cancer Incidence in Five Continents, Vol. XI, vol. 2017 Lyon, France: International Agency for Research on Cancer, 2017.

17. Ferlay J, Colombet M, Bray F. Cancer Incidence in Five Continents, CI5plus: IARC Cancer Base No.9, vol. 2018 Lyon, France: International Agency for Research on Cancer, 2018. 18. World Health Organization. WHO Mortality Database, 2019.

19. United Nations, World Population Prospects 2019: Highlights (ST/ESA/SER.A/423). Department of Economic and Social Affairs, Population Division, 2019.

20. Vale DB, Sauvaget C, Muwonge R, Ferlay J, Zeferino LC, Murillo R, Sankaranarayanan R. Disparities in time trends of cervical cancer mortality rates in Brazil. Cancer Causes Control 2016;27: 889-96.

21. Doll R, Payne P, Waterhouse J. Cancer Incidence in Five Continents: A Technical Reported. Berlin, Germany, 1966.

22. International Agency for Research on Cancer. Cl5: Cancer Incidence in Five Continents Lyon, France, 2019.

23. Luciani S, Cabanes A, Prieto-Lara E, Gawryszewski V. Cervical and female breast cancers in the Americas: current situation and opportunities for action. Bull World Health Organ 2013;91: 640-9.

24. Catterberg G, Mercado R, Informe Nacional sobre Desarrollo Humano 2017. Información para el desarrollo sostenible: Argentina y la Agenda 2030. PNUD, 2017. 
25. Apas Perez De Nucci A, Minig L, Perrotta M. Patterns of cervical cancer care in Argentina: Applying ASCO recommendations adjusted by local resources. Gynecol Oncol Rep 2017;21: 61-6.

26. Arrossi S, Ramos S, Paolino M, Sankaranarayanan R. Social inequality in Pap smear coverage: identifying under-users of cervical cancer screening in Argentina. Reprod Health Matters 2008;16: 50-8.

27. Simms KT, Steinberg J, Caruana M, Smith MA, Lew JB, Soerjomataram I, Castle PE, Bray F, Canfell K. Impact of scaled up human papillomavirus vaccination and cervical screening and the potential for global elimination of cervical cancer in 181 countries, 2020-99: a modelling study. Lancet Oncol 2019;20: 394-407.

28. Corral Cordero F, Cueva Ayala P, Yepez Maldonado J, Tarupi Montenegro W. Trends in cancer incidence and mortality over three decades in Quito - Ecuador. Colomb Med (Cali) 2018;49: 35-41.

29. Sierra MS, Soerjomataram I, Antoni S, Laversanne M, Pineros M, de Vries E, Forman D. Cancer patterns and trends in Central and South America. Cancer Epidemiol 2016;44 Suppl 1: S23-S42.

30. Chatenoud L, Bertuccio P, Bosetti C, Malvezzi M, Levi F, Negri E, La Vecchia C. Trends in mortality from major cancers in the Americas: 1980-2010. Ann Oncol 2014;25: 184353.

31. Abriata MG, Macías G, Limardo L. Suplemento atlas de mortalidad por cáncer: Argentina 2007-2011 Ciudad Autónoma de Buenos Aires: Instituto Nacional del Cáncer, 2015.

32. Barrios E, Garau M. Cáncer: magnitud del problema en el mundo y en Uruguay, aspectos epidemiológicos. Anales de la Facultad de Medicina 2017;4.

33. Hashim D, Boffetta P, La Vecchia C, Rota M, Bertuccio P, Malvezzi M, Negri E. The global decrease in cancer mortality: trends and disparities. Ann Oncol 2016;27: 926-33.

34. Arrossi S, Sankaranarayanan R, Parkin DM. Incidence and mortality of cervical cancer in Latin America. Salud Publica Mex 2003;45 Suppl 3: S306-14.

35. Ortiz AP, Soto-Salgado M, Calo WA, Tortolero-Luna G, Perez CM, Romero CJ, Perez J, Figueroa-Valles N, Suarez E. Incidence and mortality rates of selected infection-related cancers in Puerto Rico and in the United States. Infect Agent Cancer 2010;5: 10.

36. Pardo C, de Vries E. Breast and cervical cancer survival at Instituto Nacional de Cancerologia, Colombia. Colomb Med (Cali) 2018;49: 102-8.

37. Diaz A, Kang J, Moore SP, Baade P, Langbecker D, Condon JR, Valery PC. Association between comorbidity and participation in breast and cervical cancer screening: $A$ systematic review and meta-analysis. Cancer Epidemiol 2017;47: 7-19.

38. Diver EJ, Hinchcliff EM, Gockley AA, Melamed A, Contrino L, Feldman S, Growdon WB. Assessment of treatment factors and clinical outcomes in cervical cancer in older women compared to women under 65 years old. J Geriatr Oncol 2018;9: 516-9.

39. Darlin L, Borgfeldt C, Widen E, Kannisto P. Elderly women above screening age diagnosed with cervical cancer have a worse prognosis. Anticancer Res 2014;34: 5147-51. 40. Pilleron S, Soerjomataram I, Soto-Perez-de-Celis E, Ferlay J, Vega E, Bray F, Pineros M. Aging and the cancer burden in Latin America and the Caribbean: Time to act. $J$ Geriatr Oncol 2019;10: 799-804. 
Table 1. Estimated cervical cancer incidence and mortality, numbers and rates (ASR per 100,000 women-year) in Latin America and the Caribbean, by country, 2018

\begin{tabular}{|c|c|c|c|c|c|c|}
\hline \multirow[b]{2}{*}{ Population } & \multirow[b]{2}{*}{ Cases } & \multicolumn{2}{|r|}{ Incidence } & \multicolumn{3}{|r|}{ Mortality } \\
\hline & & $\begin{array}{r}\text { Uncertainty } \\
\text { interval }\end{array}$ & $\operatorname{ASR}(W)^{*}$ & Deaths & $\begin{array}{r}\text { Uncertainty } \\
\text { interval }\end{array}$ & $\operatorname{ASR}(W)^{*}$ \\
\hline Latin America and the Caribbean & 56,187 & {$[52,987-59,581]$} & 14.6 & 28,3182 & $6,658-30,081]$ & 7.1 \\
\hline Central America & 12,406 & {$[11,891-12,944]$} & 13 & 6,619 & {$[6,380-6,867]$} & 7 \\
\hline Belize & 46 & [27-79] & 28 & 25 & {$[17-40]$} & 16.2 \\
\hline Costa Rica & 351 & [263-468] & 11.2 & 192 & [152-242] & 5.6 \\
\hline El Salvador & 724 & [604-868] & 18.5 & 386 & [329-454] & 9.4 \\
\hline Guatemala & 1,503 & {$[1,300-1,737]$} & 21.1 & 793 & [700-898] & 11.7 \\
\hline Honduras & 804 & [666-970] & 19.6 & 480 & [418-551] & 12.5 \\
\hline Mexico & 7,869 & {$[7,469-8,290]$} & 11 & 4,121 & {$[3,945-4,305]$} & 5.8 \\
\hline Nicaragua & 677 & [533-859] & 21.2 & 409 & [335-500] & 13.3 \\
\hline Panama & 432 & [334-559] & 18.4 & 213 & [171-265] & 8.8 \\
\hline South America & 39,581 & {$[36,852-42,512]$} & 15.2 & 19,2351 & $8,662-19,825]$ & 7.1 \\
\hline Argentina & 4,484 & {$[4,068-4,943]$} & 16.7 & 2,231 & {$[2,053-2,425]$} & 7.7 \\
\hline Bolivia, Plurinational State of & 1,949 & {$[1,732-2,193]$} & 38.5 & 1,022 & {$[913-1,144]$} & 19 \\
\hline Brazil & 16,298 & {$[15,319-17,340]$} & 12.2 & 8,079 & {$[7,817-8,350]$} & 5.8 \\
\hline Chile & 1,549 & {$[1,301-1,845]$} & 12.2 & 725 & [636-826] & 5 \\
\hline Colombia & 3,853 & {$[3,421-4,340]$} & 12.7 & 1,775 & {$[1,615-1,951]$} & 5.7 \\
\hline Ecuador & 1,612 & {$[1,462-1,778]$} & 17.8 & 838 & [746-941] & 9 \\
\hline French Guyana & 29 & [16-52] & 20.8 & 5 & [2-12] & 3.7 \\
\hline Guyana & 124 & [99-156] & 32.7 & 64 & {$[48-86]$} & 17.3 \\
\hline Paraguay & 1,033 & {$[842-1,267]$} & 31.5 & 519 & [435-619] & 16 \\
\hline Peru & 4,103 & {$[3,776-4,459]$} & 23.2 & 1,836 & {$[1,681-2,006]$} & 10.2 \\
\hline Suriname & 85 & {$[57-126]$} & 26.8 & 47 & [33-67] & 14.3 \\
\hline Uruguay & 288 & [231-359] & 12.4 & 168 & {$[130-217]$} & 6 \\
\hline Venezuela, Bolivarian Republic of & 4,174 & {$[3,838-4,539]$} & 23.7 & 1,926 & {$[1,794-2,067]$} & 10.9 \\
\hline The Caribbean & 4,200 & {$[3,695-4,775]$} & 15.5 & 2,464 & {$[2,182-2,782]$} & 8.5 \\
\hline Bahamas & 29 & [16-51] & 10.9 & 23 & [14-38] & 7.9 \\
\hline Barbados & 38 & [22-65] & 15.5 & 27 & [17-43] & 9.4 \\
\hline Cuba & 1,231 & {$[1,065-1,423]$} & 14.6 & 597 & [529-674] & 6 \\
\hline Dominican Republic & 981 & {$[807-1,193]$} & 17.1 & 571 & [483-675] & 9.9 \\
\hline France, Guadeloupe & 39 & [26-58] & 9.3 & 19 & [11-33] & 3.3 \\
\hline France, Martinique & 32 & [22-48] & 7.6 & 14 & [8-25] & 1.9 \\
\hline Haiti & 835 & [265-2,634] & 17.1 & 563 & {$[185-1,711]$} & 12.5 \\
\hline Jamaica & 486 & [324-729] & 28.4 & 361 & [256-509] & 20.1 \\
\hline Puerto Rico & 262 & [229-300] & 10.2 & 114 & [88-148] & 3.5 \\
\hline Saint Lucia & 15 & [7-31] & 13 & 12 & {$[6-23]$} & 10 \\
\hline Trinidad and Tobago & 140 & [86-229] & 15.2 & 97 & [64-146] & 9.4 \\
\hline
\end{tabular}

${ }^{*}$ Age-standardized rates per 100,000

Source: GLOBOCAN 2018 
Table 2. Recorded cervical cancer incidence cases and rates (ASR, per 100,000 women-year) in selected Latin American and the Caribbean registries, ca. 2008-2012

\begin{tabular}{|c|c|c|c|c|c|}
\hline \multirow{2}{*}{\multicolumn{2}{|c|}{ Region/Country/Registry }} & \multicolumn{4}{|c|}{ Incidence } \\
\hline & & \multirow[t]{2}{*}{ Period } & \multirow[t]{2}{*}{ Cases } & \multirow[t]{2}{*}{ Population } & \multirow[t]{2}{*}{$\operatorname{ASR}(W)^{*}$} \\
\hline \multicolumn{2}{|c|}{ Central America } & & & & \\
\hline Costa Rica & & 2008-2011 & 1,284 & $2,234,847$ & 13.2 \\
\hline \multicolumn{6}{|c|}{ South America } \\
\hline \multirow[t]{6}{*}{ Argentina $^{\dagger}$} & & - & 2,128 & $2,741,414$ & 15 \\
\hline & Argentina, Chaco & $2008-2012$ & 684 & 536,278 & 26.5 \\
\hline & Argentina, Córdoba & $2008-2012$ & 430 & 713,427 & 10.6 \\
\hline & Argentina, Entre Rios Province & $2008-2011$ & 357 & 540,963 & 15.1 \\
\hline & Argentina, Mendoza & $2008-2012$ & 630 & 886,320 & 13 \\
\hline & Argentina, Tierra del Fuego & 2008-2012 & 27 & 64,426 & 8.9 \\
\hline \multirow[t]{7}{*}{ Brazil $^{\dagger}$} & & - & 1,444 & $2,280,906$ & 12.4 \\
\hline & Brazil, Aracaju & 2008-2012 & 210 & 301,692 & 13.1 \\
\hline & Brazil, Curitiba & 2008-2011 & 490 & 939,546 & 10.7 \\
\hline & Brazil, Florianopolis & $2008-2010$ & 123 & 212,088 & 15.6 \\
\hline & Brazil, Goiânia & 2008-2012 & 555 & 681,738 & 14.5 \\
\hline & Brazil, Jau & 2008-2012 & 40 & 67,832 & 9 \\
\hline & Brazil, Pocos de Caldas & 2008-2011 & 26 & 78,010 & 6.8 \\
\hline \multirow[t]{5}{*}{ Chile $^{\dagger}$} & & - & 725 & $1,170,607$ & 13.8 \\
\hline & Chile, Bío Bío Province & 2008-2012 & 173 & 192,466 & 14.6 \\
\hline & Chile, Concepcion & $2008-2010$ & 281 & 517,176 & 14.4 \\
\hline & Chile, Region of Antofagasta & $2008-2010$ & 121 & 270,863 & 13.2 \\
\hline & Chile, Valdivia & 2008-2012 & 150 & 190,102 & 12.9 \\
\hline \multirow[t]{5}{*}{ Colombia $^{\dagger}$} & & - & 1,887 & $2,148,204$ & 15.2 \\
\hline & Colombia, Bucaramanga & $2008-2012$ & 417 & 559,487 & 13 \\
\hline & Colombia, Cali & $2008-2012$ & 1,037 & $1,171,181$ & 15.4 \\
\hline & Colombia, Manizales & $2008-2012$ & 222 & 203,681 & 17.5 \\
\hline & Colombia, Pasto & 2008-2012 & 211 & 213,855 & 18 \\
\hline \multirow[t]{6}{*}{ Ecuador $^{\dagger}$} & & - & 2,679 & $15,305,292$ & 18.2 \\
\hline & Ecuador, Cuenca & 2008-2012 & 190 & 266,088 & 14.1 \\
\hline & Ecuador, Guayaquil & $2008-2012$ & 1,169 & $1,208,654$ & 20.2 \\
\hline & Ecuador, Loja & $2008-2010$ & 76 & 105,583 & 24.5 \\
\hline & Ecuador, Manabi & $2008-2012$ & 499 & 686,192 & 16.1 \\
\hline & Ecuador, Quito & $2008-2012$ & 745 & 836,775 & 17.6 \\
\hline \multicolumn{2}{|c|}{ French Guiana } & $2008-2012$ & 104 & 115,982 & 20.7 \\
\hline \multicolumn{6}{|l|}{ Peru } \\
\hline & Lima & $2010-2012$ & 3,161 & $4,768,406$ & 21.1 \\
\hline Uruguay & & $2008-2012$ & 1,603 & $1,754,981$ & 14.6 \\
\hline \multicolumn{6}{|c|}{ The Caribbean } \\
\hline \multirow[t]{2}{*}{ France } & & - & - & - & - \\
\hline & Martinique & $2008-2012$ & 129 & 211,844 & 7.1 \\
\hline \multirow[t]{2}{*}{ Jamaica } & & - & - & - & - \\
\hline & Kingston and St Andrew & $2008-2011$ & 233 & 342,509 & 15.6 \\
\hline Puerto Rico & & $2008-2012$ & 1,203 & $1,981,028$ & 9.3 \\
\hline
\end{tabular}


Table 3. Estimated annual percent change (EAPC, \%) and 95\% confidence interval (CI) for cervical cancer incidence and mortality rates in selected Latin America and the Caribbean cancer registries and countries

\begin{tabular}{|c|c|c|c|c|c|c|}
\hline Country/Registry & Period & $\begin{array}{l}\text { All ages } \\
\text { combined }\end{array}$ & $0-29$ y & $30-49$ y & $50-64$ y & $65+y$ \\
\hline \multicolumn{7}{|l|}{ Incidence } \\
\hline Brazil, Goiania & $2003-2012$ & $-4.2(-7.0,-1.3)$ & $-6.6(-14.3,1.9)$ & $-2.1(-5.7,1.6)$ & $-10.4(-14.3,-6.3)$ & $-10.0(-14.3,-5.4)$ \\
\hline Chile, Valdivia & $2003-2012$ & $-5.6(-10.8,-0.1)$ & $15.9(-2.9,38.4)$ & $-6.9(-12.8,-0.6)$ & $-8.9(-17.4,0.4)$ & $-9.1(-17.4,0.1)$ \\
\hline Colombia, Cali & $2003-2012$ & $-4.2(-5.3,-3.0)$ & $0.4(-5.4,6.5)$ & $-4.8(-6.6,-2.9)$ & $-4.6(-6.8,-2.4)$ & $-8.9(-11.2,-6.5)$ \\
\hline Costa Rica & $2003-2012$ & $-0.7(-3.6,2.3)$ & $10.8(3.2,19.1)$ & $-1.5(-4.3,1.5)$ & $-4.3(-8.3,-0.1)$ & $-6.6(-11.2,-1.7)$ \\
\hline Ecuador, Quito & $2003-2012$ & $0.4(-2.7,3.6)$ & $-0.1(-11,12.2)$ & $-1.3(-5.1,2.6)$ & $-3.9(-8.2,0.6)$ & $3.4(-1.3,8.3)$ \\
\hline France, Martinique & $2003-2012$ & $-3.4(-6.9,0.3)$ & $0.5(-24.4,33.7)$ & $-1.3(-8.5,6.6)$ & $-15.3(-23.6,-6.2)$ & $-2(-8.3,4.8)$ \\
\hline \multicolumn{7}{|l|}{ Mortality } \\
\hline \multicolumn{7}{|l|}{ Central America } \\
\hline Costa Rica & $2005-2014$ & $1.4(-0.8,3.6)$ & $-2.3(-15.1,12.3)$ & $1.5(-2.1,5.2)$ & $-2.4(-6.7,2.2)$ & $-1.1(-3.9,1.7)$ \\
\hline El Salvador & $2005-2014$ & $-3.6(-5.1,-1.9)$ & $-16.5(-26.5,-5.2)$ & $-6.1(-8.3,-3.8)$ & $-3.8(-6.4,-1.0)$ & $-5.1(-6.7,-3.4)$ \\
\hline Guatemala & $2006-2015$ & $-0.2(-1.8,1.4)$ & $-9.4(-16.3,-2)$ & $-2.5(-4.6,-0.4)$ & $-0.7(-3.1,1.7)$ & $-0.8(-2.5,0.8)$ \\
\hline Mexico & $2006-2015$ & $-2.1(-2.7,-1.5)$ & $1.2(-2.4,4.9)$ & $-2.5(-3.4,-1.7)$ & $-4.5(-5.4,-3.5)$ & $-4.0(-4.6,-3.3)$ \\
\hline Nicaragua & $2006-2015$ & $0.4(-1.2,2.1)$ & $-6.8(-16.9,4.6)$ & $0.0(-2.6,2.7)$ & $-4.3(-7.2,-1.2)$ & $-0.9(-3.3,1.4)$ \\
\hline Panama & $2006-2015$ & $1.3(-1.1,3.8)$ & $-10.1(-20.8,2.0)$ & $2.1(-1.4,5.7)$ & $0.3(-4.0,4.9)$ & $-1.4(-4.2,1.4)$ \\
\hline \multicolumn{7}{|l|}{ South America } \\
\hline Argentina & $2006-2015$ & $-0.1(-0.7,0.5)$ & $1.8(-1.9,5.7)$ & $0.7(-0.4,1.8)$ & $-2.2(-3.4,-0.9)$ & $-1.1(-2.0,-0.2)$ \\
\hline Brazil & $2006-2015$ & $0.3(0.0,0.5)$ & $4.0(2.4,5.6)$ & $-0.1(-0.6,0.3)$ & $-2.4(-2.9,-1.9)$ & $-2.8(-3.2,-2.5)$ \\
\hline Chile & $2006-2015$ & $-1.8(-2.9,-0.7)$ & $3.5(-4.4,12.1)$ & $-1.9(-3.8,0.1)$ & $-4.2(-6.2,-2.1)$ & $-3.8(-5.0,-2.6)$ \\
\hline Colombia & $2006-2015$ & $-1.7(-2.5,-0.8)$ & $-1.1(-4.8,2.8)$ & $-3.1(-4.1,-2.1)$ & $-4.3(-5.4,-3.1)$ & $-4.1(-4.9,-3.4)$ \\
\hline Ecuador & $2006-2015$ & $-2.7(-3.4,-1.9)$ & $-12.7(-20.1,-4.5)$ & $-3.0(-4.9,-1.1)$ & $-5.4(-7.4,-3.4)$ & $-4.0(-5.2,-2.8)$ \\
\hline Paraguay & $2005-2014$ & $-2.3(-3.6,-0.9)$ & $-5.8(-13.3,2.3)$ & $-0.7(-3.0,1.7)$ & $-5.3(-8, .0-2.6)$ & $-4.9(-6.8,-3.0)$ \\
\hline Peru & $2006-2015$ & $-1.4(-3.0,0.2)$ & $-5.0(-12.3,3.0)$ & $-3.5(-5.3,-1.8)$ & $-2.9(-4.8,-1.0)$ & $-2.6(-3.9,-1.2)$ \\
\hline Uruguay & $2006-2015$ & $-1.4(-3.3,0.5)$ & $-6.0(-21.8,13.1)$ & $-1.5(-4.9,2.1)$ & $-2.7(-6.6,1.3)$ & $-1.7(-4.2,0.8)$ \\
\hline Venezuela & $2004-2013$ & $-0.5(-1.2,0.1)$ & $-0.3(-3.3,2.8)$ & $-0.8(-1.6,0.1)$ & $-3.2(-4.3,-2.2)$ & $-2.8(-3.7,-2.0)$ \\
\hline \multicolumn{7}{|l|}{ The Caribbean } \\
\hline Cuba & $2006-2015$ & $-1.2(-2.0,-0.3)$ & $-0.2(-8.1,8.4)$ & $-4.0(-5.6,-2.4)$ & $-4.0(-5.8,-2.2)$ & $-0.8(-2.0,0.5)$ \\
\hline Dominican Republic & $2004-2013$ & $-0.1(-1.8,1.5)$ & $-5.8(-14.7,4.1)$ & $0.1(-2.9,3.2)$ & $-3.5(-7.0,0.1)$ & $-1.5(-3.6,0.6)$ \\
\hline Puerto Rico & $2006-2015$ & $2.4(0.6,4.4)$ & $-9.5(-22.4,5.6)$ & $3.3(-1.6,8.4)$ & $2.0(-3.8,8.2)$ & $0.6(-2.7,4.0)$ \\
\hline Trinidad and Tobago & $2002-2011$ & $-0.2(-3.3,3.0)$ & $-7.8(-24.2,12.0)$ & $-0.1(-4.9,5.0)$ & $4.4(-1.0,10.2)$ & $-5.0(-8.0,-1.9)$ \\
\hline
\end{tabular}




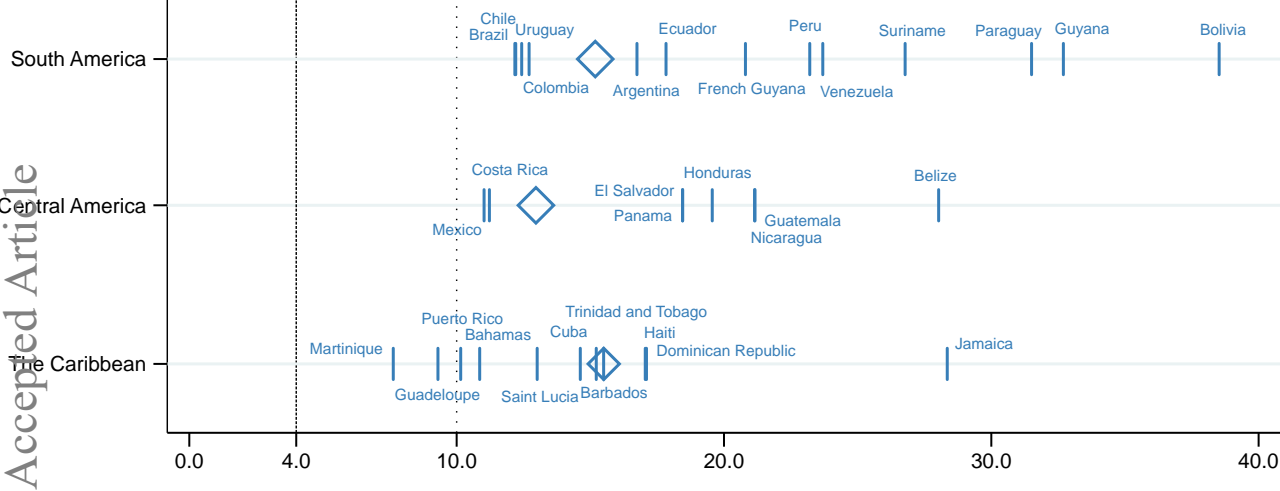

Age standardized incidence rate (per 100,000)

This article is protected by copyright. All rights reserved.

Intermediate Threshold

Country incidence estimates

Elimination Threshold defined by WHO

Sub-region incidence estimates 
Goiania, Brazil
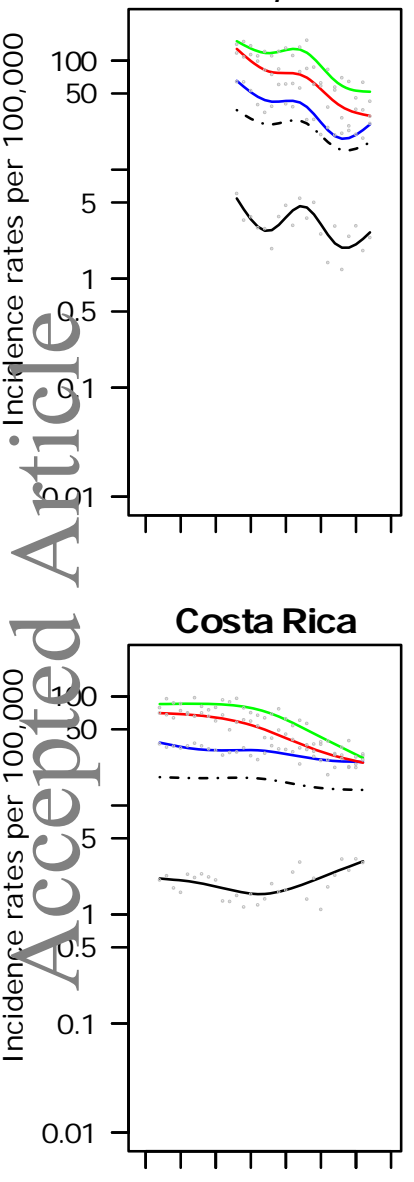

Valdivia, Chile

Cali, Colombia
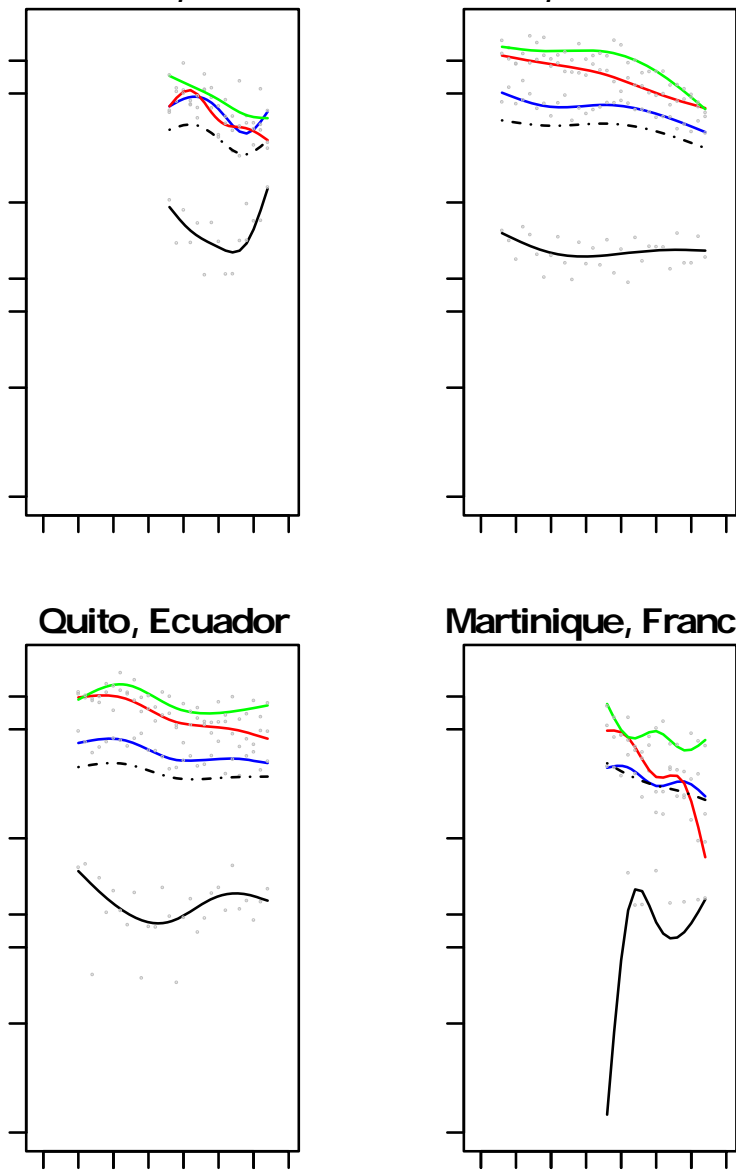

Martinique, France

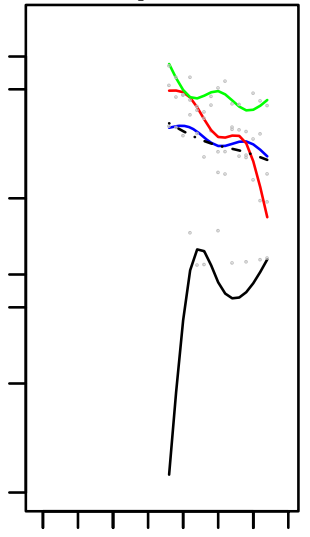

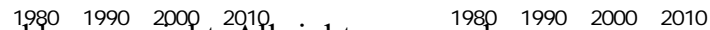
Years Years Years 
